\title{
Cenozoic evolution of deep-sea temperature from clumped isotope thermometry
} PIASECKI $^{3}$, THOMAS LEUTERT ${ }^{1}$, JOHANNA MARQUARDT $^{1}$, MARTIN ZIEGLER ${ }^{4}$, TOBIAS

AGTERHUIS $^{4}$, JAMES W. B. RAE ${ }^{5}$, JAMES S. K. BARNET ${ }^{5}$, ARADHNA TRIPATI ${ }^{6}$ AND STEFANO M. BERNASCONI ${ }^{7}$

${ }^{1}$ University of Bergen

${ }^{2}$ Open University

${ }^{3}$ Dartmouth College

${ }^{4}$ Utrecht University

${ }^{5}$ University of St Andrews

${ }^{6}$ University of California, Los Angeles

${ }^{7}$ ETH Zürich

Presenting Author: nele.meckler@uib.no

The evolution of deep-sea temperatures as extracted from the oxygen isotope composition of benthic foraminifera has been used as benchmark time series for global temperature across the last 65 million years [1]. However, the oxygen isotope signal reflects the combined influence of changes in temperature and seawater isotopic composition. Previous attempts at independent reconstruction of ocean temperature with $\mathrm{Mg} / \mathrm{Ca}$ ratios (e.g., [2]) have similarly been hampered by changes in the composition of seawater with time. Here we revisit the evolution of Cenozoic deep ocean temperature by employing clumped isotope thermometry, a palaeothermometer that is independent of water composition [3], and thus not burdened by the same assumptions as the other proxies. We have reconstructed deep ocean temperature in the North Atlantic Ocean across the Cenozoic era with an average time resolution of approximately 1 million years. We find a similar general cooling trend as seen in oxygen isotope and $\mathrm{Mg} / \mathrm{Ca}$ records, but overall warmer temperatures compared to these previous reconstructions. In addition, our data suggest previously unrecognized large temperature swings lasting several million years under late Paleocene to early Eocene ( 58-48 Ma) greenhouse conditions, which we also find indications for at Walvis Ridge in the South Atlantic. These changes could reflect either water mass reorganizations in the deep Atlantic Ocean or large-scale changes in global climate. Our results point to the assortment of influences on oxygen isotopes in benthic foraminifera having masked significant changes in early Eocene water mass properties. A reassessment of the evolution of deep ocean temperature across the Cenozoic era might therefore be needed in order to accurately understand climatic responses to tectonic events and variable greenhouse gas forcing.

References:

[1] Zachos, J., et al. (2001), Science 292, 686-693.

[2] Lear, C.H., et al. (2000), Science 287, 269-272.

[3] Eiler, J.M. (2007), Earth Planet. Sci. Lett. 262, 309-327. 